\title{
Crop Competition as a Strategy to Control Feathertop Rhodes Grass in Sorghum
}

\author{
Aman D Sharma ${ }^{13 *}$ and Daniel KY Tan ${ }^{2}$ \\ ${ }^{1}$ The University of Sydney, IA Watson Grains Research Centre, Australia, Assistant professor, Lovely professional University, Punjab, India \\ ${ }^{2}$ The University of Sydney, Sydney Institute of Agriculture, School of Life and Environmental Sciences, Faculty of Science, Australian \\ Technology Park, Australia \\ ${ }^{3}$ Assistant Professor, Lovely Professional University, Punjab, India \\ *Corresponding Author: Aman D Sharma, The University of Sydney, IA Watson Grains Research Centre, Australia and Assistant professor, \\ Lovely Professional University, Punjab, India.
}

Received: July 24, 2019; Published: August 26, 2019

DOI: $10.31080 /$ ASAG.2019.03.0630

\begin{abstract}
In sorghum, Feathertop Rhodes (FTR) (Chloris virgata) covers an area of 73,414 ha with a yield loss of 36,995 tonnes resulting in revenue loss of $\$ 7.0$ million/year. Crop competition has been suggested as a benign strategy due to weed population shifts, increase in herbicide costs and concerns of environmental pollution. We hypothesised that sorghum at high densities, when grown at narrow row spacings can suppress FTR. We aim to investigate the influence of sorghum row spacing and plant density on Feathertop Rhodes (FTR) grass growth and development. Field experiments for two successive years were conducted to study the effect of varying row spacings (50, 75 and $100 \mathrm{~cm}$ ) and sorghum densities (5, 7.5 and 10 plants $/ \mathrm{m}^{2}$ ) on the growth of FTR. Significant reduction in FTR weight was observed when surrounded by 10 sorghum plants $/ \mathrm{m}^{2}$ spaced $50 \mathrm{~cm}$ apart. The study is valuable for sorghum farmers facing the problem of FTR.

Keywords: Feathertop Rhodes Grass; Sorghum; Crop Competition; Biomass
\end{abstract}

\section{Introduction}

Sorghum is an important rotational crop in subtropical northeast Australia with a cropping area of approximately 0.82 Mha [1]. Early weed interference in sorghum can result in large yield losses [2]. Feathertop Rhodes (FTR) grass (Chloris virgata) has been identified as one of the top weeds of sorghum (Sorghum bicolor L.) along with awnless barnyard grass (Echinochloa colona) and sweet summer grass (Brachiaria eruciformis). In sorghum, FTR covers an area of 73,414 ha with a yield loss of 36,995 tonnes resulting in revenue loss of $\$ 7.0$ million/year [3,4]. Presence of herbicideresistant weeds like FTR, limited registered herbicides, and crop rotational restrictions have created a challenging environment for weed control in sorghum [5].

Sorghum growers of the subtropical north-eastern region of Australia depend on key herbicides like atrazine, metolachlor, flu- roxypyr, 2,4-D amine and glyphosate that are applied alone or mixed [6]. Very few growers use tillage (0-17\%) or crop competition (0$11 \%$ ) to manage the weeds. Although the majority of growers use pre-emergence (34-95\%) and/or post-emergence (22-57\%) herbicides without achieving effective weed control, commonly used wide-row and skip- row planting configurations have escalated the problem [6]. This has prompted the urgent need for non-chemical control options like crop competition to control weeds in sorghum.

Studies related to phenology provide important information on functional rhythms of plants and plant communities [7]. Correct prediction of weed phenological development, especially in the case of FTR is a prerequisite of weed- crop competition studies [8]. Considering sorghum as a crop competitor for FTR, we aimed to determine the: (i) effect of density of sorghum and row spacing on the biomass of FTR and (ii) the influence of sorghum plants on the phenology of FTR. 


\section{Materials and Methods}

Field studies were established in 2016 on medium clay Vertosols (pH-8.8; EC-0.13 dS/m; OC- 0.61\%) and in 2017 on medium clay Vertosols (pH-7.2; EC-0.09 dS/m; OC- 0.45\%) at the International Grains Research Centre, Narrabri.

\section{Experimental methodology}

The competition study involved two different species: Feathertop Rhodes (FTR) (Chloris virgata Sw.) and Sorghum (Sorghum bicolor; Var MR-43). In 2016, sorghum was sown in a $24 \mathrm{~m}^{2}$ plot, while FTR was broadcasted in a subplot of $2 \mathrm{~m}^{2}$. In 2017, sorghum was sown in $18 \mathrm{~m}^{2}$ plot, while FTR was transplanted in a subplot of $1 \mathrm{~m}^{2}$.

Fields were prepared with a field cultivator and recommended cultural practices for sorghum were used similarly to previous studies $[9,10]$. The experiment was arranged as a randomised complete block with four replicates. Treatments consisted of three different row spacings $(50,75$ and $100 \mathrm{~cm})$ and plant densities (5, 7.5 and 10 sorghum plants $/ \mathrm{m}^{2}$ ). In 2016, Feathertop seeds were broadcast by hand in $2 \mathrm{~m}^{2}$ subplots at the centre portion of each experimental unit similar to a previous study [11] and thinned by hand to achieve a target plant density of 5 plants $/ \mathrm{m}^{2}$, however, in 2017, Feathertop Rhodes seedlings were transplanted by hand in $1 \mathrm{~m}^{2}$ subplots at the centre portion of each experimental unit with the objective of reduction in soil weed seed bank [11]. Competition between sorghum and FTR plants was established by transplanting FTR seedlings at two- leaf stage in the subplots of the experimental units.

\section{Measurements}

Sorghum plants were harvested at maturity. FTR and sorghum samples were dried at $70^{\circ} \mathrm{C}$ for 48 hours in a dehydrator (Sterdium, Micro digital). Seed heads were weighed and threshed, dry matter and grain yield were recorded as per the previous studies [9].

The phenology of FTR was studied in the presence and absence of sorghum. Sorghum and FTR plants were transplanted at the two- leaf stage and co-established in the field. Six sorghum plants in three replicates were spaced $50 \mathrm{~cm}$ apart with the FTR plant at the centre. The field experiment for phenology of two species was initiated along with the crop competition study to evaluate the phenology of FTR in the presence or absence of sorghum [10]. At a bi-weekly interval, plant height (height from the ground to the flag leaf) of FTR was recorded using a metre ruler and the number of leaves of FTR were recorded by visual counting in the presence and absence of sorghum.

\section{Stat analysis}

No significant interactions between treatments and experimental trials were observed. Therefore, the data were pooled for each field trial for further statistical analysis. A 3 factor-factorial regression model using PROC GLM procedure (SAS 9.4) was used to test for treatment differences for the response variables of FTR and sorghum.

\section{Results}

Significant reduction in FTR weight was observed when surrounded by 10 sorghum plants $/ \mathrm{m} 2$ spaced $50 \mathrm{~cm}$ apart. Significant differences $(\mathrm{p}<0.005)$ among the treatments indicated that 10 sorghum plants per square metre, if spaced $50 \mathrm{~cm}$ apart can decrease FTR biomass (Figure 1). The finding is important for the sorghum farmers facing the problem of FTR. It clearly implies that narrow row spacing with high sorghum plant densities can reduce FTR biomass. Sorghum plants were able to suppress FTR due to their height and increased rate of growth.

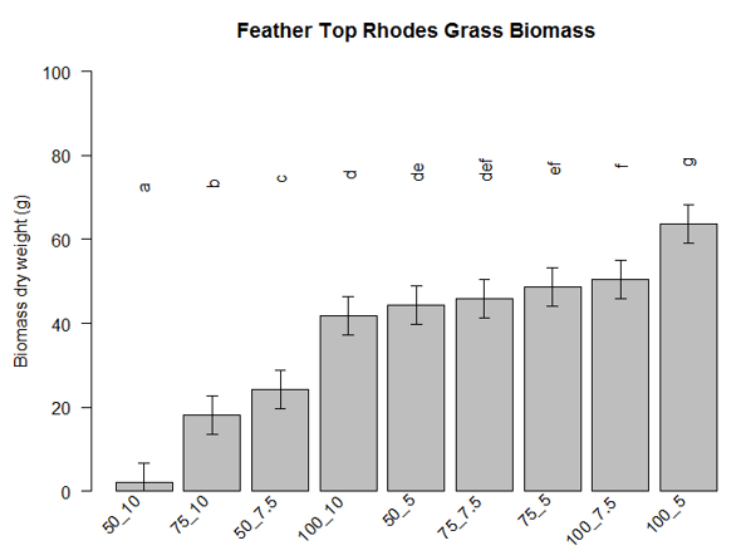

Figure 1: Interaction plot for FTR biomass at different densities and row spacings of sorghum for 2016 and 2017. In this figure $(50 \mathrm{~cm}, 75 \mathrm{~cm}$ and $100 \mathrm{~cm}$ ) represent different row spacings, while $(5,7.5$ and 10$)$ represent number of sorghum plants per metre square. 
Grain yield of sorghum was increased with the decrease in FTR biomass (Figure 2).

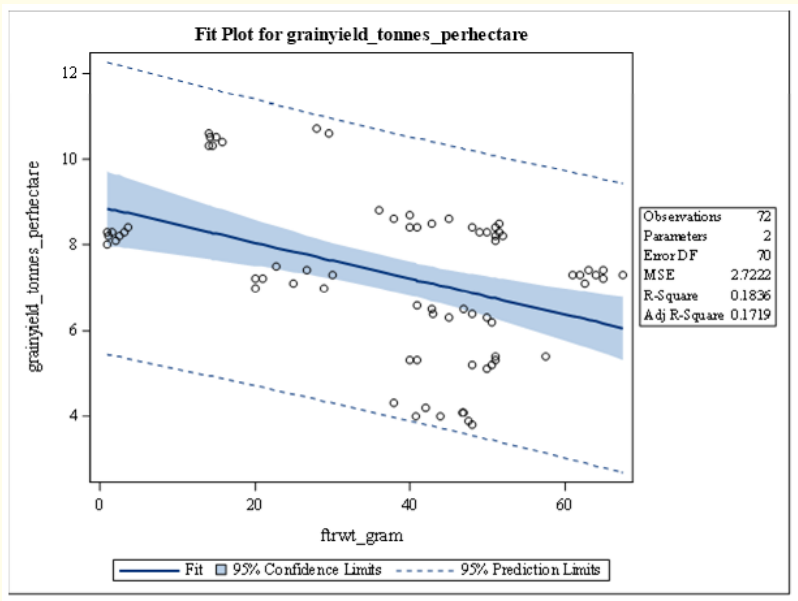

Figure 2: Interaction plot shows a decrease in FTR biomass (g) with the increase in grain yield (tonnes/ha) of sorghum.

Highest biomass and grain yield of sorghum was observed at 75 $\mathrm{cm}$ spacing when surrounded by 10 plants $/ \mathrm{m}^{2}$ (Figure 3, Figure 4). Interaction plots for sorghum biomass (Figure 3) indicated $28 \%$ increase in sorghum biomass in the absence of FTR, while there was $80 \%$ increase in grain yield (Figure 4 ) of sorghum in the absence of FTR. Significant interactions ( $p<0.001$ ) between row spacing and densities of sorghum plants with respect to biomass and grain production of sorghum were observed. Differences in harvest index ( 0.12 with FTR and 0.10 without FTR) (Figure 5) demonstrated the negative effect of FTR on the biomass and grain yield of sorghum.

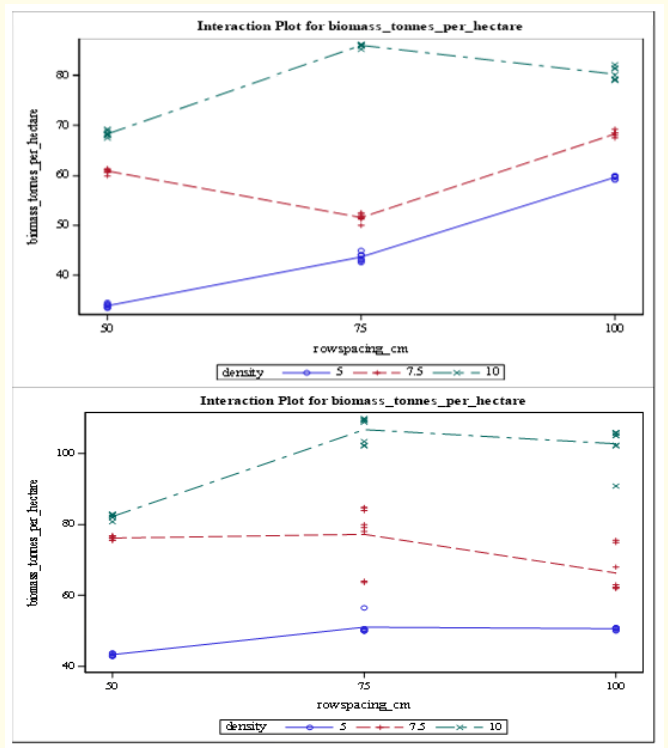

Figure 3: Interaction plot for biomass (tonnes/ha) of sorghum at varying row spacings $(50 \mathrm{~cm}, 75 \mathrm{~cm}$ and $100 \mathrm{~cm})$ and densities of sorghum plants $(5,7.5$ and 10 plants per metre square) in the presence (above) and absence (below) of FTR.

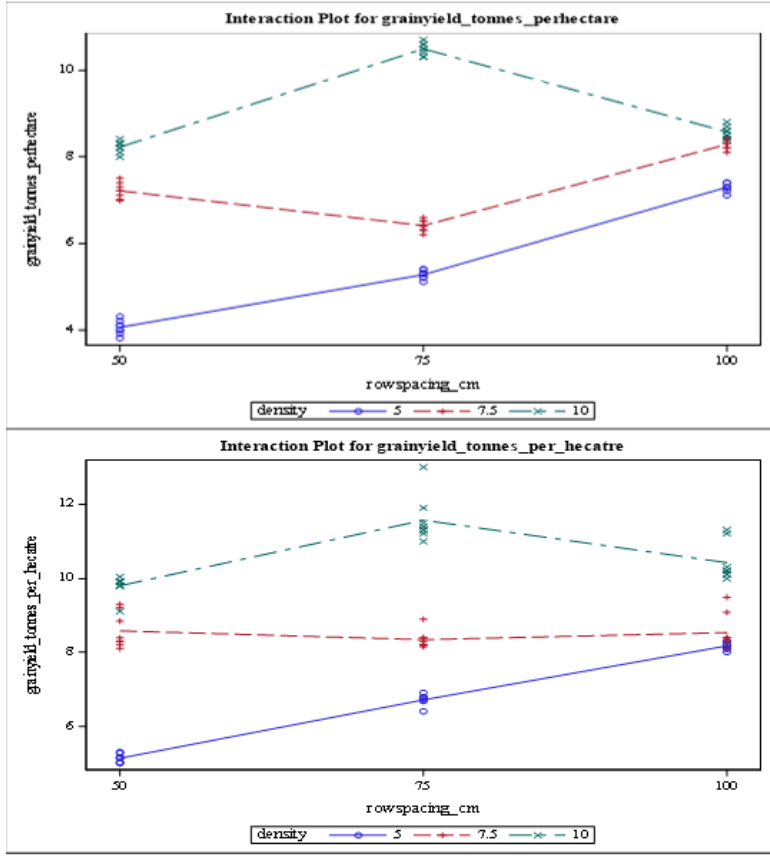

Figure 4: Interaction plot for grain yield (tonnes/ha) of sorghum at varying row spacings $(50 \mathrm{~cm}, 75 \mathrm{~cm}$ and $100 \mathrm{~cm})$ and densities of sorghum plants $(5,7.5$ and 10 plants per metre square) in the presence (above) and absence (below) of FTR.

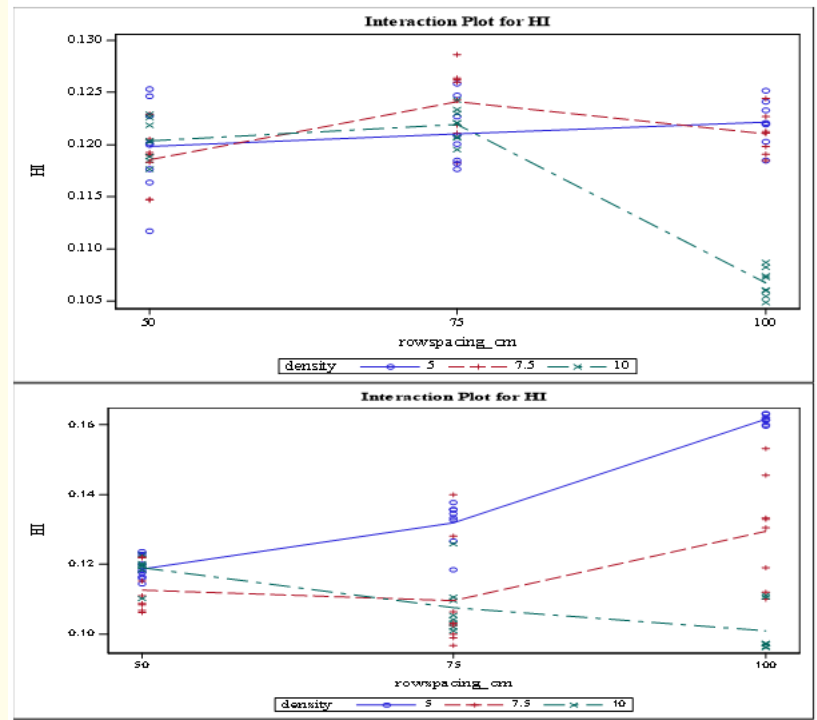

Figure 5: Interaction plot for Harvest index (HI) of sorghum at varying row spacings $(50 \mathrm{~cm}, 75 \mathrm{~cm}$ and $100 \mathrm{~cm})$ and densities of sorghum plants $(5,7.5$ and 10 plants per metre square $)$ in the presence (above) and absence (below) of FTR.

Phenology of FTR with and without competition with sorghum

FTR plant without competition with sorghum showed more lateral growth, while the FTR in competition with sorghum plants showed more vertical growth. This is an adaptation of FTR plant 
due to competition by sorghum plants. Sorghum plants suppressed the growth of FTR by shading effect. The absence of light due to shading effect of sorghum resulted in decreased growth of FTR. After 28 days, there was no leaf production in FTR plants facing competition from sorghum (Table 1) while leaf production continued in FTR plants in the absence of sorghum plants. An increase in height of FTR plants in competition with sorghum was observed (Table 2) in comparison to control plots. This is an adaptation by the FTR plant for the competition for light with sorghum plant. There was an eight-fold decrease in shoot weight of FTR compared with shoot weight of sorghum and four times decrease in the root weight of FTR compared with root weight of sorghum in the phenology study. This finding clearly indicates that sorghum is a better competitor than FTR.

\begin{tabular}{|l|c|c|c|c|}
\hline $\begin{array}{l}\text { Number } \\
\text { of Leaves } \\
\text { of FTR }\end{array}$ & $\mathbf{1 4}$ days & $\mathbf{2 8}$ days & $\mathbf{4 2}$ days & $\mathbf{5 6}$ days \\
\hline Control & $17( \pm 0.33)$ & $55( \pm 0.57)$ & $242( \pm 0.57)$ & $281( \pm 0.57)$ \\
\hline $\begin{array}{l}\text { With } \\
\text { sorghum }\end{array}$ & $11( \pm 0.33)$ & $36( \pm 0.33)$ & $36( \pm 0.33)$ & $36( \pm 0.33)$ \\
\hline
\end{tabular}

Table 1: Phenological aspects of FTR in competition with sorghum.

The numbers in the parentheses are the standard errors of the mean $(n=3)$; FTR = Feather top Rhodes

\begin{tabular}{|l|c|c|c|c|}
\hline $\begin{array}{l}\text { Height of } \\
\text { FTR }(\mathbf{c m})\end{array}$ & $\mathbf{1 4}$ days & $\mathbf{2 8}$ days & $\mathbf{4 2}$ days & $\mathbf{5 6}$ days \\
\hline Control & $15( \pm 0.33)$ & $32( \pm 0.33)$ & $35( \pm 0.33)$ & $42( \pm 0.33)$ \\
\hline $\begin{array}{l}\text { With sor- } \\
\text { ghum }\end{array}$ & $10( \pm 0.57)$ & $47( \pm 0.57)$ & $77( \pm 0.57)$ & $78( \pm 0.33)$ \\
\hline
\end{tabular}

Table 2: Phenological aspects of FTR in competition with sorghum.

The numbers in the parentheses are the standard error of the mean $(n=3)$; FTR = Feather top Rhodes

\section{Discussion}

From our experiments, higher sorghum densities (10 plants/ $\left.\mathrm{m}^{2}\right)$ at narrow row spacing $(50 \mathrm{~cm})$ resulted in the suppression of FTR, which is in agreement with previous studies $[12,13]$. The decrease in grain yield of sorghum was observed with the increase in FTR biomass, which is in agreement with another study in which
Japanese millet (Echinochloa esculenta) adversely reduced the seed production of sorghum [1].

Our findings are in agreement with a previous study in which sorghum yield from $45-\mathrm{cm}$ row spacing was considerably higher compared with 60 and $90 \mathrm{~cm}$ row spacings due to the reduction in weed biomass [14]. The reason for the reduction in weed biomass of FTR was narrowly spaced sorghum plants sown in proximity which resulted in narrow leaves, long stems and root biomass that increased the sorghum plant biomass $[15,16]$. It implies that sorghum can be sown at narrow row spacings with higher densities to suppress the growth of FTR. Higher sorghum densities mean a higher seeding rate while the costs of seed would be compensated with a reduction in weed control costs (i.e., chemicals, fuel, machinery, and labour) [17].

Higher densities of sorghum in field trials resulted in the reduction of FTR biomass due to non-penetration of light $[5,18]$. As plants mature and the canopy closes, the competition for photosynthetically active radiation (PAR) becomes intense [19] for crop and weed plants. Sorghum can absorb incoming light more efficiently than weeds [5] and absence of light due to canopy closure of sorghum plants resulted in the reduction of FTR biomass.

\section{Conclusion}

Phenological aspects of FTR indicated non-production of leaves in FTR plants after four weeks (Table 1), while facing competition from sorghum. It clearly indicates the competition for resources (light, water, and nutrients) between sorghum and FTR plants in which sorghum was found to be a strong competitor. An increase in height of FTR in the presence of sorghum plants (Table 2) was an adaptation to capture light. Competition for light was the major reason for the reduction in weed biomass in previous studies [20], which implies that maximising light interception in sorghum crop canopies with high densities at narrow spacings can suppress FTR.

\section{Bibliography}

1. Wu HW., et al. "Competition of sorghum cultivars and densities with Japanese millet (Echinochloa esculenta)". Weed Biology and Management 10 (2010): 185-193.

2. Werle R., et al. "Distribution of Herbicide-Resistant Shattercane and Johnsongrass Populations in Sorghum Production Areas of Nebraska and Northern Kansas". Agronomy Journal 108 (2016): 321-328. 
3. Werth J., et al. "Changes in weed species since the introduction of glyphosate-resistant cotton". Crop and Pasture Science 64 (2013): 791-798.

4. Llewellyn R., et al. "Impact of weeds on Australian grain production: the cost of weeds to Australian grain growers and the adoption of weed management and tillage practices" (2016).

5. Grichar WJ., et al. "Effect of row spacing and herbicide dose on weed control and grain sorghum yield". Crop Protection 23 (2004): 263-267.

6. Walker SR., et al. "A survey of management and economic impact of weeds in dryland cotton cropping systems of subtropical Australia". Australian Journal of Experimental Agriculture 45 (2005): 79-91.

7. Ralhan PK., et al. "Phenological characteristics of the tree layer of kumaun himalayan forests". Vegetatio 60 (1985): 91-101.

8. Deen W., et al. "Photothermal time describes common ragweed (Ambrosia artemisiifolia L.) phenological development and growth". Weed Science 46 (1998): 561-568.

9. Knezevic SZ., et al. "Relative time of redroot pigweed (Amaranthus retroflexus $\mathrm{L}$ ) emergence is critical in pigweed-sorghum Sorghum bicolor (L) Moench competition". Weed Science 45 (1997): 502-508.

10. Ward MJ., et al. "Cover Crops and Disturbance Influence Activity-Density of Weed Seed Predators Amara aenea and Harpalus pensylvanicus (Coleoptera: Carabidae)". Weed Science 59 (2011): 76-81.

11. Smith RG., et al. "Cover-Crop Species as Distinct Biotic Filters in Weed Community Assembly". Weed Science 63 (2015): 282295.

12. Andrade., et al. "Yield responses to narrow rows depend on increased radiation interception". Agronomy Journal 94 (2002): 975-980.

13. Mashingaidze., et al. "Narrow rows reduce biomass and seed production of weeds and increase maize yield". Annals of Applied Biology 155 (2009): 207-218.

14. Bishnoi., et al. "Response of no-till and conventionally planted grain-sorghum to weed-control method and row spacing". Plant and Soil 129 (1990): 117-120.
15. Bullock DG., et al. "A growth analysis comparison of corn grown in conventional and equidistant distant plant spacing". Crop Science 28 (1988): 254-258.

16. Kasperbauer MJ and Karlen DL. "Plant spacing and reflected far-red light effects on phytochrome-regulated photosynthate allocation in corn seedlings". Crop Science 34 (1994): 15641569.

17. Weiner J., et al. "Suppression of weeds by spring wheat Triticum aestivum increases with crop density and spatial uniformity". Journal of Applied Ecology 38 (2001): 784-790.

18. Ramesh K., et al. "Role of crop competition in managing weeds in rice, wheat, and maize in India: A review". Crop Protection 95 (2017): 14-21.

19. Holt JS. "Plant-responses to light - A potential tool for weed management". Weed Science 43 (1995): 474-482.

20. Ballare CL and Casal JJ. "Light signals perceived by crop and weed plants". Field Crops Research 67 (2000): 149-160.

\section{Volume 3 Issue 9 September 2019}

\section{(C) All rights are reserved by Aman D Sharma and Daniel} KY Tan . 